\title{
Geomorfologia, potencial erosivo e fertilidade dos solos cultivados com laranja lima em Santana do Mundaú - AL
}

\author{
Geomorphology, erosion potential and fertility of soils cultivated with orange lime \\ Santana Mundaú - AL
}

\section{José Thales Pantaleão Ferreira ${ }^{1}$, Elvis Pantaleão Ferreira ${ }^{2}$, Kelizângela Nascimento Albuquerque ${ }^{3}$, Gildivan dos Santos Silva ${ }^{4}$, Fabiana Souza Pantaleão ${ }^{5}$}

\begin{abstract}
Resumo - As características geomorfológicas do relevo têm relevante importância nos processos erosivos do solo. A erosão trata-se de um processo natural importante para evolução da paisagem, contudo a erosão acelerada devido ao uso irregular do solo gera inúmeros problemas sociais e ambientais. O presente trabalho teve como objetivo, analisar a relação entre a geomorfologia, potencial erosivo e fertilidade dos solos cultivados com laranja lima em Santana do Mundaú-AL. Foram confeccionados mapas de declividade, altitude e solos; levantamento de dados fotográficos; realizadas análises para caracterização física e química dos solos em seis pomares. A combinação de vários fatores tais como: sistema de plantio do tipo "morro abaixo", de transporte, predominância de relevo ondulado a fortemente ondulado, presença de solos do tipo Argissolo e ausência de práticas conservacionistas de conservação do solo favorecem a ação dos agentes erosivos do solo e perda da fertilidade nas áreas cultivadas com laranja lima. Quanto aos teores de nutrientes verifica-se que Cigarra > Cocal I > Cocal II > Chã de Areia II > Chã de Areia I > Jussara. Os dois últimos pomares necessitam principalmente de adubação que eleve os teores de $\mathrm{Ca}^{2+}$ e $\mathrm{K}^{+}$respectivamente. Os baixos teores de matéria orgânica e muito baixos de fósforo nos solos são os principais limitantes à produção agrícola dos pomares estudados.
\end{abstract}

Palavras-chave: relevo, erosão, laranja lima, Citrus.

\begin{abstract}
The geomorphological characteristics of relief have significant importance in soil erosion. The erosion it is a natural process important for landscape evolution, however accelerated erosion due to irregular use of soil generates many social and environmental problems. This study aimed to analyze the relationship between the geomorphology, erosion potential and fertility of cultivated soils with lime orange in Santana do Mundau-AL. We made maps of slope, altitude and soil; photographic survey data, conducted analyzes for physical and chemical characterization of soils in six orchards. A combination of several factors such as: planting system like "downhill" transport, dominance of the heavily undulated wavy presence of Ultisol soil type and lack of conservation practices for soil conservation favor the action of erosive agents and loss of soil fertility in cultivated areas with lime orange. As for nutrient content shows that Cicada $>$ Cocal I > Cocal II > Sand II Cha > Cha de Areia I > Jussara. The latter two require particularly orchards fertilizer that elevates levels of $\mathrm{Ca}^{2+}$ and $\mathrm{K}^{+}$respectively. The low organic matter content and very low phosphorus soils are the main limiting factors for agricultural production orchards studied.
\end{abstract}

Keywords: topography, erosion, lime orange, Citrus.

\section{INTRODUÇÃO}

A geomorfologia é designada como a ciência que tem a incumbência de estudar os fenômenos que ocorrem e que interferem diretamente na formação do relevo. Seu estudo representa uma importante ferramenta capaz de simplesmente, as diversas formas do relevo. disponibilizar subsídios para as causas da ocorrência de um determinado tipo de relevo, levando em consideração os agentes internos e externos modeladores desse (Gendaszek et. al., 2012). Portanto, a geomorfologia caracteriza-se como a ciência que tem como objeto de estudo as irregularidades da superfície terrestre, ou

A característica da geomorfologia local tem relevante importância nos processos erosivos nos solos brasileiros,

Recebido em aceito em

${ }^{1}$ Doutorando em Agronomia: Solos e Nutrição de Plantas, Universidade Federal do Ceará (UFC). Departamento de Ciências do Solo/CCA/UFC. Av. Mister Hull, 2977 - Campus do Pici, Bloco 807; 60440-554, Fortaleza - Ceará. E-mail: thalespantaleao@ gmail.com

${ }^{2}$ Técnico em Agricultura do Departamento de Solos, Instituto Federal do Espírito Santo (IFES). Rodovia ES-080, Km 21 - São João de Petrópolis, 29660-000, Santa Teresa-ES.

${ }^{3}$ Graduanda em Geografia, Universidade Federal de Alagoas (UFAL). Campus A. C. Simões - Av. Lourival Melo Mota, s/n, Tabuleiro dos Martins, 57072-900, Maceió-AL.

${ }^{4}$ Mestrando em Agronomia: Solos e Nutrição de Plantas, Universidade Federal do Ceará (UFC). Departamento de Ciências do Solo/CCA/UFC. Av. Mister Hull, 2977 - Campus do Pici, Bloco 807; 60440-554, Fortaleza - Ceará.

${ }^{5}$ Graduanda em Ciências Biológicas pelo Instituto Federal do Espírito Santo (IFES). Rodovia ES-080, Km 21 - São João de Petrópolis, 29660-000, Santa Teresa-ES. 
principalmente em virtude das características climáticas do Brasil. Quanto maior a declividade e o comprimento de rampa de uma área, maiores serão as possibilidades de o solo ser erodido. Contudo, o processo erosivo é natural, sendo importante para a formação e modelagem da paisagem e rejuvenescimento dos solos, mas passa a ser um problema quando a erosão se torna acelerada, em níveis danosos ao ambiente, ocorrendo geralmente por ações antrópicas, como a abertura de estradas, ocupação irregular das terras, práticas inadequadas de manejo dos solos, entre outros (Pires e Souza, 2006).

A erosão do solo tem um alto custo para toda economia mundial. Estes custos são resultantes de efeitos da erosão no local e fora dele. No local os efeitos são particularmente oriundos de áreas agrícolas, ocorrendo perda de solo (principalmente da camada mais fértil), perda de nutrientes, desagregação da estrutura, redução dos teores de matéria orgânica, redução da profundidade efetiva do solo, diminuição da umidade e consequente declínio da sua fertilidade, gerando insegurança alimentar, podendo chegar ao abandono de áreas agrícolas. Os efeitos fora do local podem ser visualizados pelo assoreamento de rios, represas e lagos, pela eutrofização das águas e liberação de $\mathrm{CO}^{2}$ para atmosfera, contribuindo para o aquecimento global (Morgan, 2005).

O Estado de Alagoas é o terceiro maior produtor de laranja do Nordeste, sendo superado pelos Estados da Bahia e Sergipe (Ibge, 2011). Contudo, diferentemente dos demais Estados, sua produção é basicamente composta por cultivos de laranja lima, concentrada na região do Vale do Mundaú, que compreende os municípios de União dos Palmares, São José da Laje, Ibateguara, Branquinha e Santana do Mundaú. Este último é responsável por aproximadamente $90 \%$ da produção do Estado segundo Seplande (2011).

Conforme discutido por Ferreira et al. (2012) os pomares de laranja lima (Citrus sinensis (L.) Osbeck) cultivados em Santana do Mundaú - AL, sofrem com a ação erosiva dos solos em função das características geomorfológicas da região, que possui topografia irregular com relevo movimentado e também em decorrência do histórico manejo inadequado dos pomares que são cultivados com a ausência de técnicas conservacionista do solo e da água, potencializando a ação dos agentes erosivos do solo. Além disso, pouco se sabe cientificamente sobre a real situação da fertilidade dos solos cultivados com laranja lima (Citrus sinensis (L.) Osbeck).

À luz destas implicações, o presente trabalho teve como objetivo realizar uma análise da relação entre a geomorfologia local, potencial erosivo e fertilidade dos solos cultivados com laranja lima (Citrus sinensis (L.) Osbeck) no município de Santana do Mundaú, Estado de Alagoas.

\section{MATERIAIS E MÉTODOS}

O presente estudo foi realizado no município de Santana do Mundaú - AL (figura 1), cuja população é composta por 10.961 habitantes, área territorial de 224,82 km2 e se distancia de Maceió, capital do Estado, em aproximadamente $98 \mathrm{~km} \quad$ (CPRM, 2005).

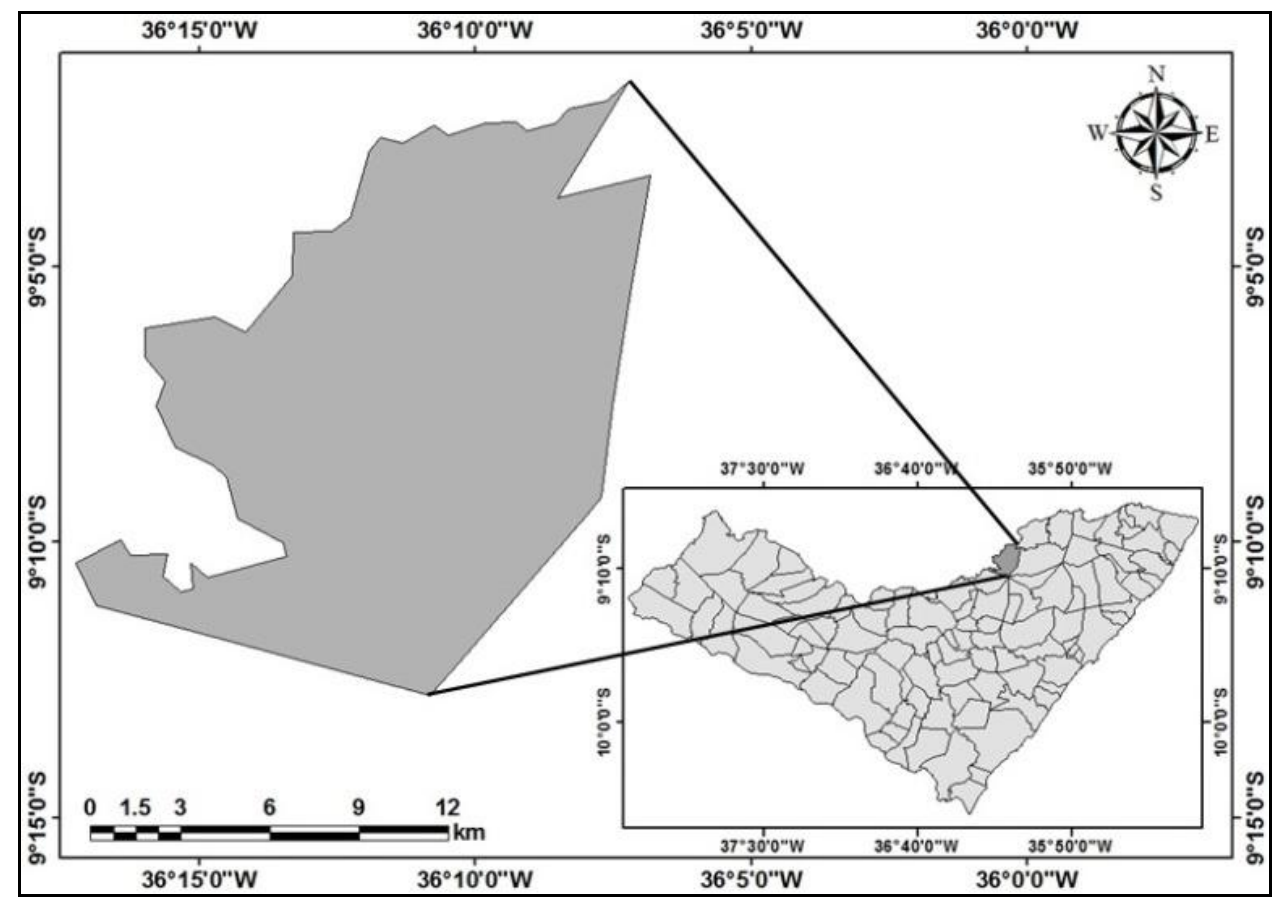

Figura 1. Localização do município de Santana do Mundaú no mapa do Estado de Alagoas. Fonte: Os autores (2012).

As avaliações foram feitas pela análise de mapas fotográficos, análises exploratórias e qualitativas das (declividade, altitude e solos), levantamento de dados características geomorfológicas, agronômicas e ambientais 
da área estudada. As avaliações foram realizadas em campo, onde as situações foram observadas e registradas da forma como ocorrem, mediante contato direto e interativo do pesquisador com a situação objeto de estudo, apresentando como característica essencial o enfoque descritivo.

A elaboração cartográfica digital do mapa de altitude em relação ao nível do mar e da declividade do Município, foi realizada com auxílio do software ArcGis 10.0, utilizando dados SRTM adquiridos no site do Grupo Americano em Pesquisa e Agricultura Internacional (<http://srtm.csi.cgiar.org/SELECTION/inputCoord.asp >) - O mapa de altitude em relação ao nível do mar foi elaborado dividindo-se o terreno em oito classes de altitude de 100 em 100 metros, até o grupo máximo de altitude de 600 metros. O mapa de declividade foi elaborado com cinco classes de declividade em percentagem, que compreendem os relevos planos (0-3\%), suave ondulado (4-8\%), ondulado (9-20), forte ondulado (21-45\%) e montanhoso (46-75,82\%).

O mapa de solos foi elaborado com dados do Levantamento Exploratório - Reconhecimento de solos do Estado de Alagoas na escala de 1:400.000 (Jacomine et al., 1975).

A caracterização dos atributos físicos e químicos dos solos foi realizada em seis tradicionais propriedades rurais que cultivam laranja lima (Citrus sinensis (L.) Osb.) denominados Chã de Areia I (S 09 15 '11,4', W $36^{\circ} 22^{\prime} 28,3^{\prime}$ ', $405.1 \mathrm{~m}$ de altitude), Chã de Areia II (S $09^{\circ}$ $15^{\prime} 15,4^{\prime}$ ' W $36^{\circ} 22^{\prime} 30,3^{\prime}$ ', $403.2 \mathrm{~m}$ de altitude), Cocal I (S 09 $15^{\prime}$ 65,0', W 36 24' 25,6', $249.6 \mathrm{~m}$ de altitude), Cocal II (S 09 ${ }^{\circ} 15^{\prime} 67,8^{\prime}$ ' W 36 24' 03,6', $230.5 \mathrm{~m}$ de altitude), Cigarra (S 09 $16^{\prime}$ '07,5' W $36^{\circ} 17^{\prime}$, 56,9', 250.3 m de altitude) e Jussara (S $09^{\circ} 18^{\prime} 20,3^{\prime \prime}$ W $36^{\circ} 21^{\prime}$ ' $66,1^{\prime \prime}, 382.7 \mathrm{~m}$ de altitude). Os pomares estudados possuem mais de 20 anos de cultivos, sem qualquer utilização de adubos químicos, orgânicos e prática de calagem.

Neste sentido, em cada pomar estudado, foram separadas glebas homogêneas e realizada as coletas de amostras de solos segundo as recomendações da Embrapa (1997). Em cada local de estudo, realizou-se a coleta de 12 amostras simples, na profundidade de 0-20 cm. Após as coletas, as amostras compostas foram encaminhadas ao laboratório, secas ao ar, destorroadas, passadas em peneira com malha de $2 \mathrm{~mm}$ de abertura e procedidas as análises químicas (pH em água, $\mathrm{Ca}, \mathrm{Mg}, \mathrm{K}, \mathrm{Na}, \mathrm{Al}, \mathrm{H}+\mathrm{Al}, \mathrm{CO}$ ) e físicas (granulometria pelo método da pipeta) conforme recomendações da EMBRAPA (1997).

A partir dos dados das análises químicas foram obtidos os valores da capacidade de troca de cátions (CTC), soma de bases (S), saturação de bases (V\%), saturação por alumínio (m\%).

Os dados das análises químicas foram analisados estatisticamente pelo teste de Tukey ao nível de 5\% de significância, por meio do programa Assistat.

\section{RESULTADOS E DISCUSSÃO}

A cidade de Santana do Mundaú é a maior produtora de laranja lima do Estado de Alagoas, responsável por aproximadamente $90 \%$ de toda a produção estadual (Ferreira et al., 2012). A produção de laranja lima é quase toda cultivada em áreas que apresentam relevo movimentado, classificado principalmente como ondulado a fortemente ondulado (Figura 2). A declividade acentuada desta região potencializa ação dos agentes erosivos do solo, principalmente no tocante a ação da chuva, onde chega a chover cerca de $1.600 \mathrm{~mm}$ por ano (CPRM, 2005), concentrados principalmente nos meses de abril, maio, junho e julho.

O clima da região é do tipo Tropical Chuvoso com verão seco. O período chuvoso tem início em fevereiro e término em outubro. A vegetação natural é predominantemente do tipo Floresta Subperenifólia, com partes de Floresta Subcaducifólia e cerrado/floresta (CPRM, 2005). Entretanto, a pastagem e a citricultura são a cobertura vegetal que mais predomina na região atualmente.

Segundo dados publicados pela Companhia de Pesquisa de Recursos Minerais (CPRM, 2005) o município de Santana do Mundaú encontra-se geologicamente inserido na Província Borborema, representada principalmente pelos litótipos Belém do São Francisco (insere leuco-ortognaisses tonalíticogranodioríticos migmatizados e enclaves de supracrustais) e da Suíte Itaporanga calcialcalina de médio a alto potássio (engloba granitos e granodioritos porfiríticos, associados a dioritos). Estas características litológicas influenciam diretamente a geomorfologia e tipo de solos presentes em Santana do Mundaú-AL.

A altitude em relação ao nível do mar da região estudada é bem variável conforme se observa na figura 2B, encontrando-se áreas mais baixas na faixa de 150 a 200 metros de altitude, as quais se encontram próximas dos corpos hídricos, dando origem a uma forma de vale à região, onde se concentra as áreas urbanizadas da cidade, susceptível a fortes enchentes. Na parte mais oeste e norte da região concentram-se as áreas de maiores altitudes, alcançando a faixa de 500 a 600 metros.

Os solos de Santana do Mundaú-AL estão representados na figura 3. São formados principalmente pelas classes de Argissolos Amarelos e Argissolos Vermelho-Amarelos que ocupam as principais áreas com relevo ondulado a fortemente ondulado, conforme pode ser verificado na figura $2 \mathrm{~A}$. 


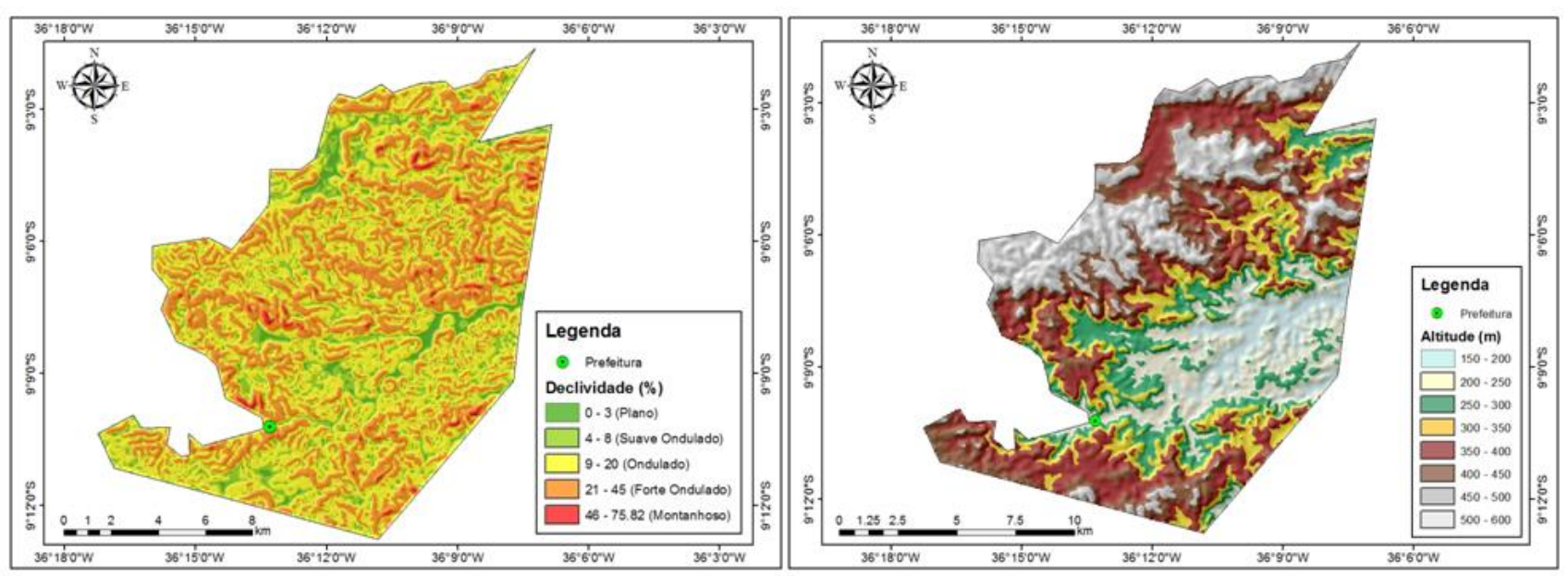

Figura 2. Mapa declividade (A) e altitude (B) ao nível do mar do município de Santana do Mundaú - AL. Fonte: Os autores (2013).

A classe dos Argissolos compreende solos que se caracterizam principalmente por possuírem horizonte B textural imediatamente abaixo de um horizonte A ou E (Oliveira, 2008). A presença de horizonte B textural reduz a capacidade de infiltração de água, pois o mesmo possui maior quantidade de argila que os horizontes acima, dificultando a drenagem de água, que associado a condição topográfica do município (figuras $2 \mathrm{~A}$ e $2 \mathrm{~B}$ ) e as características climáticas da região, com precipitações anuais acima de $1.600 \mathrm{~mm}$ (CPRM, 2005), possui elevado potencial erosivo, com possibilidade de haver ocorrência de deslizamentos de solo, desabamentos e corridas de lama mobilizando blocos fraturados, em caso de excesso de precipitação e desestabilização das vertentes. Para evitar a erosão e degradação destes solos, deve-se fazer uso de manejos agrícolas mais sustentáveis, mantendo sempre uma cobertura vegetal no solo, evitando que as gotas de água da chuva incidam diretamente sobre o solo e que este seja arrastado para outro local, retirando a camada de solos mais férteis, e consequentemente reduzindo a produção agrícola.

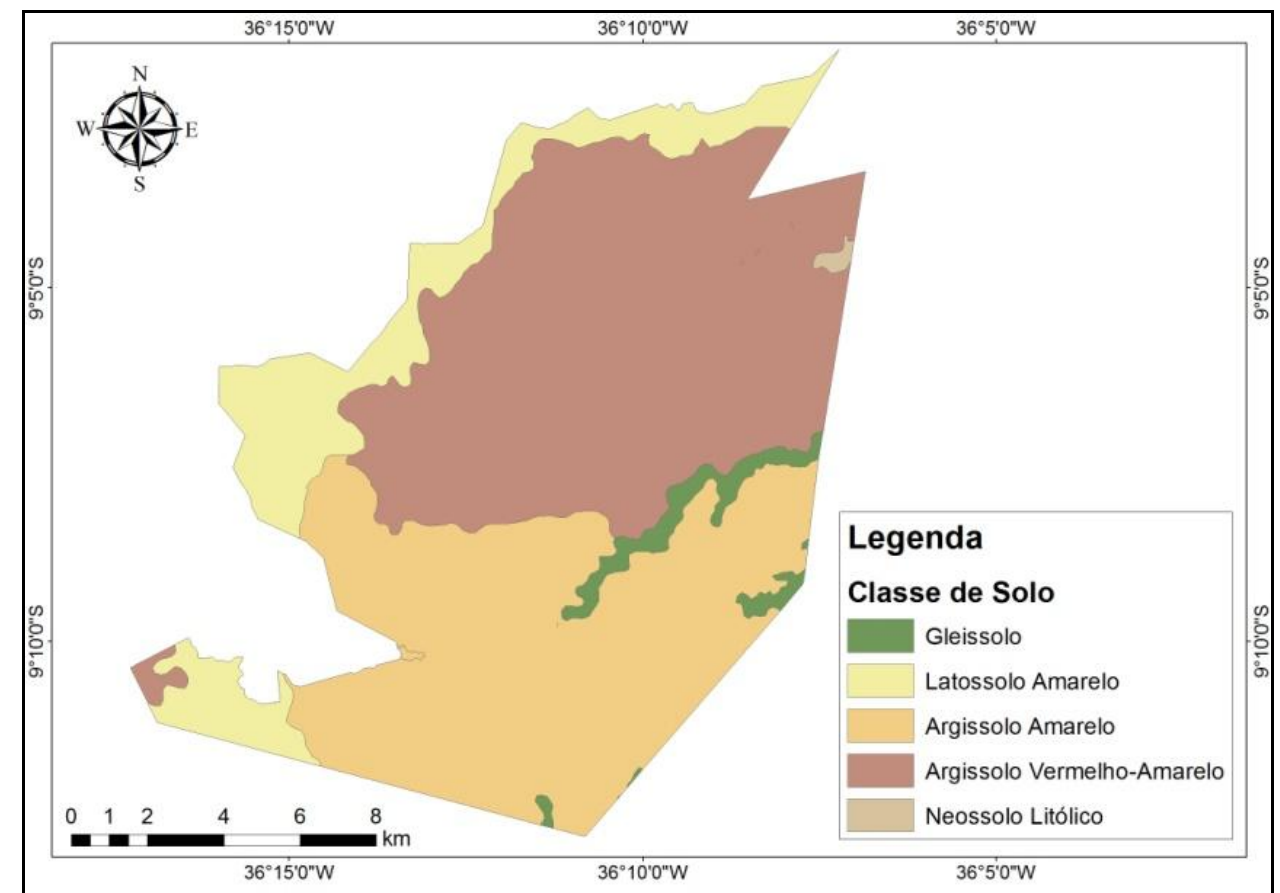

Figura 3. Mapa de solos de Santana do Mundaú - AL. Fonte: Os autores (2013). 
A classe dos Latossolos Amarelos é a segunda mais extensa em Santana do Mundaú, conforme apresentado na figura 3 , ocupando a parte mais oeste e norte do mapa, onde estão os relevos menos movimentados (figura $2 \mathrm{~A} \mathrm{e}$ 2B). Estes solos são caracterizados por apresentarem avançado estágio de intemperismo, sendo profundos, bem drenados, ácidos e quimicamente pobres em sua maioria (Oliveira, 2008). Estas características fazem com que esta classe de solo tenha reduzido potencial de erosão, mesmo nas condições de elevada precipitação (acima de 1600 $\mathrm{mm}$ ) da região (CPRM, 2005).

A classe dos Gleissolos está presente na parte mais baixa do relevo, próximo ao curso dos rios e mananciais da região (Figuras 2A, 2B e 3 ). Esses solos são hidromórficos e caracterizam-se por apresentar horizonte Glei iniciando dentro dos primeiros $150 \mathrm{~cm}$ de profundidade, imediatamente abaixo de um horizonte $\mathrm{A}$ ou E, ocupando as planícies aluviais com excesso de água durante grande parte do ano, apresentando forte limitação ao uso (Oliveira, 2008).

E com muito menor expressão tem-se os Neossolos Litólicos na parte leste do mapa (Figura 4), região mais próxima ao agreste do Estado de Pernambuco e possivelmente em uma área onde predomina menor precipitação. Os Neossolos litólicos são solos pouco profundos, não ultrapassando $30 \mathrm{~cm}$ de profundidade, possui limitação ao desenvolvimento radicular e elevado potencial erosivo em virtude de sua reduzida profundidade e exposição aos fatores erosivos (Oliveira, 2008).

Um dos indicadores mais importantes da degradação do solo é a estabilidade de agregados, que pode ser definida como a resistência do solo contra os efeitos externos destrutivas das chuvas por meio do escoamento, e vento (Saygina et al., 2012). O teor de matéria orgânica dos solos está indiretamente relacionado com a estabilidade de agregados do solo, pois a mesma tem a capacidade de unir partículas primárias para formação de agregados. A matéria orgânica possibilita maior agregação do solo e, com isso, maior resistência aos agentes erosivos do solo (Bronick e Lal, 2005). Os teores de matéria orgânica dos solos dos pomares estudados (tabela 1) são baixos, típicos de regiões de clima tropical úmido, influenciando o potencial de agregação do solo, mas que pode ser compensado pela ação de outros agentes agregantes como: os óxidos, ciclos de umedecimento e secagem e teor e tipo de argila, entre outros.

A caracterização granulométrica dos solos estudados indica que os solos dos pomares Chã de Areia I, Cocal I e Cocal II são classificados como franco-argilo-arenosos; o pomar Cigarra como franco-argiloso; o pomar Chã de Areia II como argiloso e o Jussara como franco-arenosso (tabela 1). Esses resultados indicam que na profundidade avaliada $(0-20 \mathrm{~cm})$, possivelmente estes solos possuem boa drenagem de água e boa aeração. Contudo, perdem umidade facilmente devido a baixa retenção de água pela fração areia, exceto na localidade Chã de Areia II que possui $41,9 \%$ de argila.

Dessa forma, podem apresentar maior suscetibilidade ao processo erosivo, em função do elevado teor de areia, pois esta fração tem pouca capacidade de agregação, podendo ser facilmente carreada pela água da chuva nas condições do relevo local aliados aos baixos teores de matéria orgânica. Este comportamento também condiz com as características químicas avaliadas, onde os solos mais arenosos representados pelos pomares Chã de Areia I e Jussara, com $69,5 \%$ e $77,7 \%$ de areia, respectivamente, apresentaram também os menores teores de nutrientes e consequentemente baixa fertilidade (tabela 2).

As análises de fertilidade demonstraram que somente no pomar Cigarra o $\mathrm{pH}$ foi caracterizado como de fraca acidez, com valor de 6,40, sendo semelhante estatisticamente aos pomares Chã de Areia II, Cocal I e Cocal II (tabela 2). Segundo os critérios de Alvarez et al. (1999), os solos dos pomares de laranja lima avaliados possuem $\mathrm{pH}$ caracterizados, em sua maioria, como de média acidez, variando de 5,15 a 5,95.

Os pomares estatisticamente com maior acidez do solo foram: Chã de Areia I (pH 5,15) e Jussara (pH 5,20). Os valores de $\mathrm{pH}$ menores correspondem aos pomares com menor teor de argila e silte e elevada quantidade da fração areia com valores de 69,5 e $77,7 \%$, respectivamente (tabela 2). Os solos arenosos geralmente possuem uma mineralogia essencialmente quartzosa, refletindo em solos com baixa capacidade de retenção de cátions, elevada acidez, reduzido poder tampão de $\mathrm{pH}$ e nutrientes, e caráter distrófico, a exemplo dos pomares Chã de Areia I e Jussara que também possuem estatisticamente os maiores valores para acidez trocável, entretanto, estes valores são caracterizados como muito baixo e baixo, respectivamente (tabela 2) (Alvarez et al., 1999).

Segundo Horst et al. (2010) o alumínio na solução do solo nas formas monoméricas inorgânicas, particularmente como $\mathrm{Al}^{3+}$, é considerado fitotóxico, reduzindo o alongamento celular, o que impede o crescimento radicular (Souza et al., 2006) e consequentemente o desenvolvimento das plantas. No presente estudo, as plantas de laranja lima estão livres destes problemas, pois os valores de acidez trocável $\left(\mathrm{Al}^{3+}\right)$ observados nos solos estudados foram baixos, na profundidade de $0-20 \mathrm{~cm}$ conforme apresentado na (tabela 2). 
Tabela 1. Granulometria e matéria orgânica de alguns solos cultivados com laranja lima em Santana do Mundaú - AL.

\begin{tabular}{cccccc}
\hline Locais Estudados & Argila & Silte & Areia & Classe Textural & $\begin{array}{c}\text { MO } \\
\text { dag/kg }\end{array}$ \\
& ------------- dag/kg & & & \\
\hline Chã de Areia I & 23.4 & 7.1 & 69.5 & franco-argilo-arenoso & 1,93 \\
Chã de Areia II & 41.9 & 13.9 & 44.2 & argiloso & 1,79 \\
Cocal I & 25.4 & 12.4 & 62.3 & franco-argilo-arenoso & 1,63 \\
Cocal II & 29.8 & 13.8 & 56.3 & franco-argilo-arenoso & 1,44 \\
Cigarra & 38.6 & 19.5 & 41.8 & franco-argiloso & 1,82 \\
Jussara & 18.7 & 3.6 & 77.7 & franco-arenoso & 1,78 \\
\hline
\end{tabular}

Tabela 2. Atributos químicos de solos cultivados com laranja lima em seis pomares de Santana do Mundaú - AL.

\begin{tabular}{|c|c|c|c|c|c|c|c|c|c|c|c|c|c|}
\hline Locais Estudados & $\begin{array}{c}\text { pH } \\
\left(\mathrm{H}_{2} \mathrm{O}\right)\end{array}$ & $\mathrm{Al}^{3+}$ & $\mathbf{H}+\mathbf{A l}$ & $\mathrm{Ca}^{2+}$ & $\mathrm{Mg}^{2+}$ & $\begin{array}{r}\mathbf{K}^{+} \\
\mathrm{c} / \mathrm{kg}----\end{array}$ & $\mathrm{Na}^{+}$ & CTC & S.B & V & m & $\begin{array}{c}P \\
\mathrm{mg} / \mathrm{kg}\end{array}$ & $\begin{array}{c}\text { M.O } \\
\text { dag/kg }\end{array}$ \\
\hline Chã de Areia I & $5,15 \mathrm{~b}$ & $0,14 \mathrm{ab}$ & $5,15 \mathrm{ab}$ & $0,95 \mathrm{c}$ & $1,20 \mathrm{~cd}$ & $0,18 \mathrm{bc}$ & $0,01 \mathrm{~b}$ & $7,49 \mathrm{~b}$ & $2,34 \mathrm{c}$ & $31,24 \mathrm{bc}$ & $5,64 \mathrm{a}$ & $3,53 \mathrm{~b}$ & $1,93 \mathrm{a}$ \\
\hline Chã de Areia II & $5,75 \mathrm{ab}$ & $0,00 \mathrm{c}$ & $4,99 a b$ & $2,29 a b$ & $1,44 \mathrm{bc}$ & $0,11 \mathrm{c}$ & $0,01 \mathrm{~b}$ & $8,84 \mathrm{ab}$ & $3,85 \mathrm{~b}$ & $43,55 a b$ & $0,00 \mathrm{~b}$ & $2,84 \mathrm{c}$ & $1,79 \mathrm{ab}$ \\
\hline Cocal I & $5,95 \mathrm{ab}$ & $0,00 \mathrm{c}$ & $3,64 \mathrm{~b}$ & $2,79 a b$ & $1,69 \mathrm{abc}$ & $0,41 \mathrm{a}$ & $0,02 \mathrm{~b}$ & $8,52 a b$ & $4,91 \mathrm{ab}$ & $57,62 \mathrm{a}$ & $0,00 \mathrm{~b}$ & $2,95 \mathrm{c}$ & $1,63 \mathrm{bc}$ \\
\hline Cocal II & $5,80 \mathrm{ab}$ & $0,05 \mathrm{bc}$ & $4,56 \mathrm{~b}$ & $2,24 \mathrm{~b}$ & $2,14 \mathrm{a}$ & $0,33 \mathrm{ab}$ & $0,05 \mathrm{a}$ & $9,32 \mathrm{ab}$ & $4,76 a b$ & $51,07 \mathrm{a}$ & $1,04 \mathrm{~b}$ & $3,96 \mathrm{a}$ & $1,44 \mathrm{c}$ \\
\hline Cigarra & $6,40 \mathrm{a}$ & $0,00 \mathrm{c}$ & $5,07 \mathrm{ab}$ & $2,84 \mathrm{a}$ & $1,99 \mathrm{ab}$ & $0,34 \mathrm{ab}$ & $0,03 \mathrm{ab}$ & $10,27 \mathrm{a}$ & $5,20 \mathrm{a}$ & $50,63 \mathrm{a}$ & $0,00 \mathrm{~b}$ & $3,30 \mathrm{~b}$ & $1,82 \mathrm{ab}$ \\
\hline Jussara & $5,20 \mathrm{~b}$ & $0,24 \mathrm{a}$ & $8,08 \mathrm{a}$ & $1,24 \mathrm{c}$ & $0,74 \mathrm{~d}$ & $0,05 \mathrm{c}$ & $0,02 \mathrm{~b}$ & $10,13 \mathrm{a}$ & $2,05 \mathrm{c}$ & $20,23 \mathrm{c}$ & $10,48 \mathrm{a}$ & 3,96 a & $1,78 \mathrm{ab}$ \\
\hline $\mathrm{CV}(\%)$ & 3.13 & 47.69 & 21.57 & 9.97 & 16.51 & 24.61 & 28.13 & 11.79 & 5.29 & 16.76 & 56.15 & 3.29 & 4.28 \\
\hline
\end{tabular}

As médias seguidas da mesma letra não diferem estatisticamente entre si, pelo teste Tukey, ao nível de 5\% de probabilidade. 
Os pomares de laranja da região foram implantados sem a adoção de qualquer técnica de conservação do solo. Os plantios foram realizados sem a utilização de curva de nível, também popularmente denominado "morro abaixo" (figura 4), facilitando a erosão e degradação dos solos. Conforme levantamentos realizados por Ferreira et al.
(2012), esse procedimento de plantio em "morro abaixo" em épocas de chuvas vem ocasionando, em locais pontuais do município, problemas de desestabilização de encostas com a ocorrência de deslizamentos de solo e corridas de lama, mobilizando blocos fraturados e provocando o assoreamento de rios e lagoas.

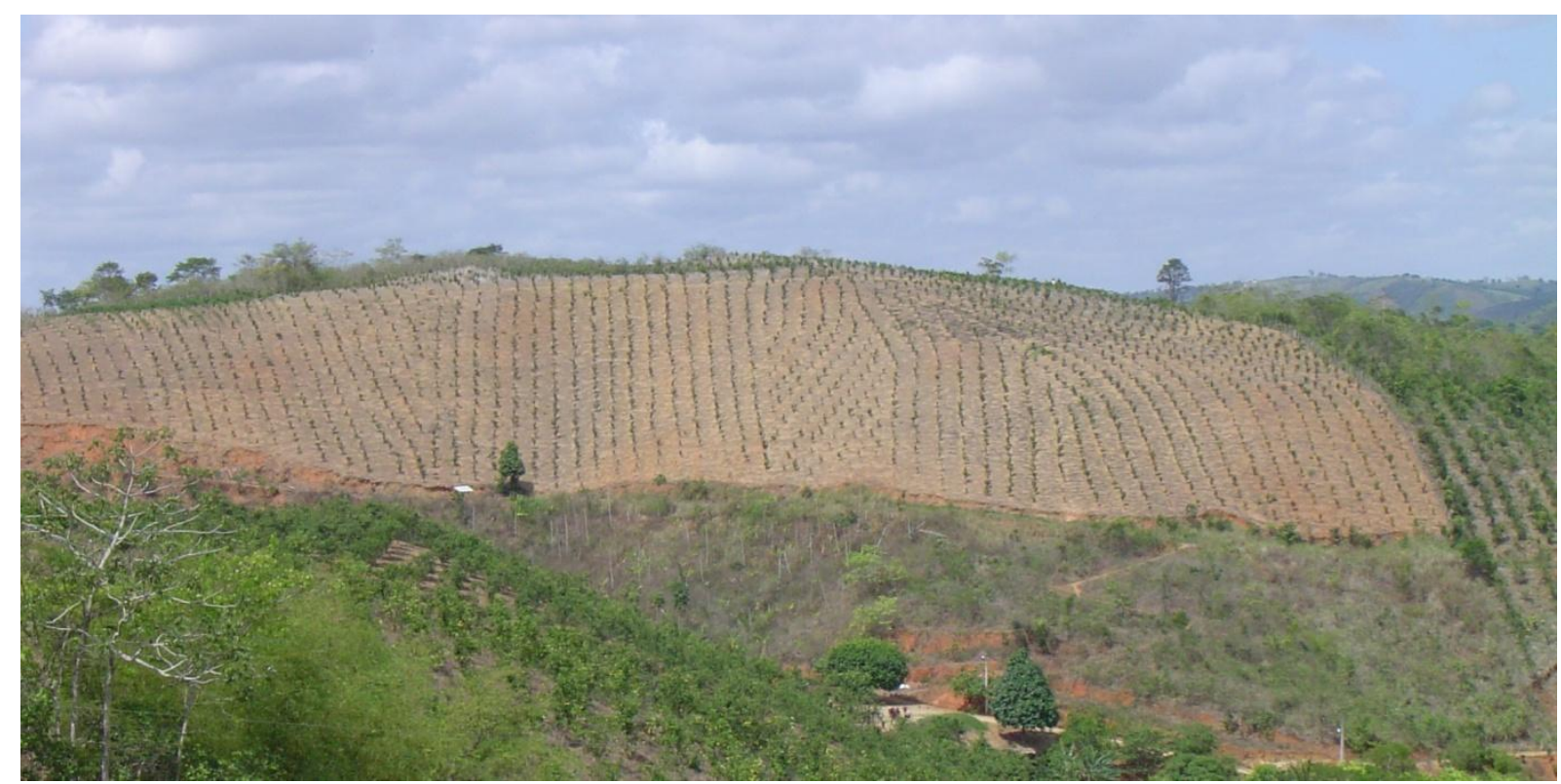

Figura 4. Plantio de laranja lima do tipo "morro a baixo" a favor da declividade do terreno em Santana do Mundaú AL. Fonte: Os autores (2013).

Os teores trocáveis de $\mathrm{Ca}^{2+}$ variaram de 0,95 a 2,79 $\mathrm{cmol}_{\mathrm{c}} \mathrm{kg}^{-1}$, caracterizados como de baixo a alto teores de $\mathrm{Ca}^{2+}$ (Alvarez V. et al., 1999). Os maiores teores foram verificados no pomar Cocal I com 2,79 $\mathrm{cmol}_{\mathrm{c}} \mathrm{kg}^{-1}$, não diferindo estatisticamente dos pomares Cocal II, Chã de Areia II e Cigarra. Os piores teores, estatisticamente foram para Chã de Areia I e Jussara, que não diferiram estatisticamente, com 0,95 e $1,24 \quad \mathrm{cmol}_{\mathrm{c}} \quad \mathrm{kg}^{-1}$, respectivamente.

Os teores trocáveis de $\mathrm{Mg}^{2+}$ e $\mathrm{K}^{+}$foram os que apresentaram as maiores disponibilidades para as plantas, variando em sua grande maioria de teores médios a muito altos $\left(0,74\right.$ a 2,14 cmolc $\mathrm{kg}^{-1}$ para $\mathrm{Mg}^{2+}$ e 0,11 a 0,41 cmolc $\mathrm{kg}^{-1}$ para $\mathrm{K}^{+}$), onde somente o pomar Jussara que apresentou teores classificados com médio para $\mathrm{Mg}^{2+} \mathrm{e}$ baixo para $\mathrm{K}^{+}\left(0,74\right.$ cmolc $\mathrm{kg}^{-1}$ e 0,05 cmolc $\mathrm{kg}^{-1}$, respectivamente), o que faz necessário uma adubação potássica (Alvarez V. et. al., 1999). Estatisticamente os maiores teores $\mathrm{Mg}^{2+}$ e $\mathrm{K}^{+}$foram obtidos pelos pomares Cocal I, Cocal II e Cigarra, que não diferiram entre si, e o menor teor foi verificado para o pomar Jussara que diferiu de todos os demais pomares para o teor de $\mathrm{Mg}^{2+}$ e foi semelhante aos pomares Chã de Areia I e Chã de Areia II para os teores de $\mathrm{K}^{+}$, apesar de apresentar teores bem mais baixo que estes últimos.

Segundo Roccuzzo et al. (2012) as plantas cítricas tendem a absorver mais $\mathrm{Ca}^{2+}$ do que $\mathrm{K}^{+}$, acumulando o $\mathrm{Ca}^{2+}$ principalmente na casca dos frutos. Neste caso, observa-se que apesar de não haver histórico de aplicação de fertilizantes nos pomares, em sua maioria, os solos dos pomares avaliados estão suprindo bem a necessidade de $\mathrm{Ca}^{2+}$ e $\mathrm{K}^{+}$das plantas de laranja lima. Isto deve ser explicado pela litologia presente em algumas áreas que possuem Suíte Itaporanga calcialcalina de médio a alto potássio (engloba granitos e granodioritos porfiríticos, associados a dioritos) (CPRM, 2005). Contudo, atenção especial deve-se dar ao pomar Chã de Areia I quanto ao suprimento de $\mathrm{Ca}^{2+}$, que facilmente pode ter seu teor elevado com a correção da acidez do solo, com a utilização de calcário, e ao pomar Jussara quanto ao teor de $\mathrm{K}^{+}$, que apresentou níveis baixos.

É importante ressaltar que os baixos teores de $\mathrm{K}^{+}$ podem acarretar em plantas menos resistentes a seca; menor resistência a pragas e doenças; menor resistência ao acamamento; alteração nos teores de vitamina C dos frutos; menor período de armazenamento dos frutos e várias desordens fisiológicas (Meurer et al., 2006).

Os teores trocáveis de $\mathrm{Na}^{+}$em todos os pomares foram baixos (tabela 2), variando de 0,01 a $0,05 \mathrm{cmol}_{\mathrm{c}} \mathrm{kg}^{-1}$, reflexo das elevadas precipitações pluviométricas do município de Santana do Mundaú, que chove em média $1.600 \mathrm{~mm}$ anuais, sendo caracterizado como um clima do tipo tropical chuvoso com verão seco.

A CTC e a SB dos solos variaram de média a alta, conforme critérios de Alvarez V. et al. (1999). A CTC mais elevada foi verificada para o pomar Cigarra que 
apresentou 10,27 $\mathrm{cmol}_{\mathrm{c}} \mathrm{kg}^{-1}$ não diferindo estatisticamente dos pomares Jussara, Chã de Areia II, Cocal I e Cocal II. A menor CTC foi apresentada pelo pomar Chã de Areia I, contudo, vale salientar que apesar da CTC dos solos serem consideradas de média a alta, esta possui suas cargas ocupadas com grande quantidade de $\mathrm{H}+\mathrm{Al}$, chegando a ocupar $79,7 \%, 68,7 \%, 56,4 \%, 49,36,48,9 \%, 42,7 \%$ da CTC dos solos dos pomares Jussara, Chã de Areia I, Chã de Areia II, Cigarra, Cocal II e Cocal I, respectivamente (tabela 2).

Para SB destaca-se o pomar Cigarra com 5,20 $\mathrm{cmol}_{\mathrm{c}}$ $\mathrm{kg}^{-1}$, sendo estatisticamente semelhante aos pomares Cocal I e Cocal II (tabela 2). Os pomares Jussara e Chã de Areia I não diferiram estatisticamente entre si e apresentaram os menores resultados para SB, embora, segundo os critérios de Alvarez V. et al. (1999), estes ainda são classificados como valores médios.

A Saturação de Bases (V\%) indica que os solos dos pomares Cocal I, Cocal II e Jussara são eutróficos, não diferindo estatisticamente entre si, juntamente com o pomar Chã de Areia II apesar de ser distrófico. Os menores valores de V\% foram observados nos pomares Chã de Areia I e Jussara, que não diferem entre si, sendo classificados como distróficos (tabela 2).

Os baixos teores de Matéria Orgânica - MO e muito baixos de $\mathrm{P}$ (Fósforo) são os atributos mais críticos que foram observados em todos os solos estudados (tabelas $1 \mathrm{e}$ 2), comprometendo a produtividade agrícola dos pomares de laranja lima. Segundo Ramos et al. (2009), essa diminuição pode ser em decorrência da decomposição da matéria orgânica ser extremamente rápida em regiões de clima tropical. Essa decomposição se intensifica em solos sem proteção superficial.

Os teores mais elevados de $\mathrm{P}$ foram verificados para os pomares Cocal II e Jussara com 3,96 mg kg-1, que não diferem entre si estatisticamente, entretanto, ainda são classificados como teores muito baixos (Alvarez V. et al., 1999). Segundo Roccuzzo et al. (2012) o sistema radicular da planta cítrica apresenta 22 e $33 \%$ da biomassa total, reduzindo seu crescimento e desenvolvimento quando a planta encontra-se deficiente em $\mathrm{P}$, fato que pode estar acontecendo nos pomares estudados.

A elevada quantidade da fração areia verificada principalmente nos pomares Chã de Areia I e Jussara (tabela 2), influencia o teor de $\mathrm{P}$ em solução, pois a reduzida densidade de carga a e menor superfície específica, em comparação com a fração argila, aumenta a disponibilidade de $\mathrm{P}$ em solução. Porém, a capacidade de manter a concentração deste em solução é baixa, pois os solos arenosos apresentam baixa capacidade tampão de $\mathrm{P}$.

Apesar da produção de laranja lima do município de Santana do Mundaú - AL ser conduzida historicamente de modo rústico, com pouca tecnificação e sem realizar práticas essenciais de manejo como adubação e calagem, a maioria dos solos apresentam boas condições de fertilidade, caracterizados como eutróficos. Contudo, a situação dos solos dos pomares Chã de Areia I e Jussara são os mais críticos entre as áreas estudadas. Observa-se que o fator mais limitante da fertilidade dos solos estudados são os teores de $\mathrm{P}$ e $\mathrm{MO}$, devendo-se realizar um manejo conservacionista que aumente o aporte de material orgânico ao solo, e adubações ricas em fósforo para que a produtividade das plantas de laranja lima se eleve.

Entretanto, a forma rústica e extrativista de conduzir os pomares de laranja lima deve ser abolida, pois põe em risco a sustentabilidade dos cultivos agrícolas, podendo sofrer com quedas de produtividades crescentes e aumento da infestação de pragas e doenças. Esta forma de cultivo contribui para o surgimento da erosão acelerada que afeta negativamente as características químicas e físicas do solo, contribuindo para o seu empobrecimento. Segundo Politano e Pisarra (2005), extensões muito consideráveis com processos erosivos intensos e muito intensos causam, além do empobrecimento do solo, alteração muito perceptível da conformação da superfície do terreno geradas pelo escavamento das posições mais altas localizadas a montante e pelo soterramento das posições mais baixas do terreno, representadas principalmente pelas planícies de inundação ou várzeas.

Segundo Santos Filho et al. (2005) este tipo de plantio era comum antigamente, hoje essa prática é inaceitável e, quando acontece, reflete uma inoperância dos serviços de assistência técnica e extensão rural dos órgãos locais. Os autores complementaram ainda que este procedimento de plantio pode causar um generalizado problema de desequilíbrio ambiental.

De acordo com Pires e Souza (2006) a erosão acelerada atinge taxas elevadíssimas quando a exploração agropecuária utiliza práticas de cultivo inadequadas. Entre as 9 (nove) práticas que intensificam o processo erosivo do solo citadas pelos autores, constata-se 7 (sete) práticas usualmente utilizadas nos pomares de laranja lima, que são: monocultivos; plantio de culturas pouco protetoras do solo; plantio "morro abaixo"; queima dos restos culturais; inobservância da capacidade de uso ou aptidão agrícola da terra e, para finalizar, o cultivo em terreno inclinado sem a utilização de práticas conservacionistas. Esta constatação torna preocupante a segurança alimentar e a sustentabilidade dos pomares de laranja lima, principalmente em virtude de sua importância socioeconômica para toda cidade e região.

Para reduzir o risco de erosão acelerada e degradação destes solos nas condições edafoclimáticas e topográficas predominantes no município (figuras 1, 2, 3 e 4), deve-se fazer adoção de manejos agrícolas mais sustentáveis, com a utilização de práticas conservacionistas de conservação do solo e da água. A preservação da palhada (restos de galhos, folhas, etc.) é uma prática que se encaixa nos moldes conservacionistas. Canellas et al. (2003), ao trabalhar com cana de açúcar, verificaram que a adição de matéria orgânica através da preservação da palhada, por ocasião da colheita ou pela adição de vinhaça, alterou as propriedades químicas do solo e proporcionou melhoria na fertilidade do solo e na qualidade da matéria orgânica do mesmo. 
Neste contexto, os autores Pires e Souza, (2006) apontam que as práticas conservacionistas mecânicas buscam aumentar a infiltração de água no solo; diminuir o comprimento do declive; segmentar o comprimento total das vertentes e reduzir a velocidade, volume e concentração do escoamento superficial. Estes benefícios podem ser alcançados com a implantação de terraceamento e plantio em contorno.

Ainda conforme os autores, as práticas conservacionistas vegetativas aumentam a proteção do solo; o teor de matéria orgânica no solo; o teor de nutrientes para as plantas e melhoraram a estrutura do solo, que pode ser conseguido com a utilização de faixas homeostáticas; culturas em faixas de retenção; rotação de culturas; capinas alternadas; ceifa do mato e uso de cobertura morta. A manutenção da vegetação nas áreas mais íngremes é um fator importante para conservação do solo e da água, pois quando há vegetação as gotas de água da chuva incidem sobre as folhas e se infiltra de forma adequada no solo, evitando assim que a parte do solo mais fértil seja carregada pela chuva.

As práticas conservacionistas edáficas também estão relacionadas com o controle da erosão do solo, manutenção e melhoria da fertilidade e produtividade dos solos, que podem ser alcançadas com o uso das terras de acordo com a aptidão agrícola; preservação da vegetação natural em áreas indicadas pelo código florestal brasileiro; evitar o uso do fogo no preparo de áreas; uso de práticas corretivas (calagem, gessagem, potassagem e fosfatagem) e práticas de adubação (Pires e Souza, 2006).

Contudo, para os autores Pires e Souza (2006) a melhor proteção do solo e da água aos agentes erosivos é alcançada com a utilização combinada das práticas mecânicas, vegetativas e edáficas. A utilização de apenas uma das práticas pode reduzir a eficiência no controle do risco de erosão acelerada.

É oportuno destacar que em Santana do Mundaú as laranjas depois de colhidas são transportadas do campo para as estradas por "muares", animais adaptados ao transporte de cargas, equipados com cestos denominados de "caçoares e cangaias", tendo em vista a limitação da paisagem, principalmente em locais de topografia irregular (Ferreira et al., 2012). Este sistema de transporte requer muitas vezes a abertura de pequenas estradas nas áreas, criando condição de desestabilização da encosta e compactação do solo, podendo vir a causar deslizamentos de solo, corridas de lama e mobilização de blocos fraturados, além de favorecer a concentração de água e a geração de sulcos que podem evoluir para ravinas e voçorocas.

\section{CONSIDERAÇÕES FINAIS}

A combinação de vários fatores tais como: sistema de plantio do tipo "morro abaixo", de transporte, predominância de relevo ondulado a fortemente ondulado, presença de solos do tipo Argissolo e ausência de práticas conservacionistas de conservação do solo favorecem a ação dos agentes erosivos do solo e perda da fertilidade nas áreas cultivadas com laranja lima.

Quanto aos teores de nutrientes verifica-se que Cigarra $>$ Cocal I > Cocal II > Chã de Areia II > Chã de Areia I > Jussara. Os dois últimos pomares necessitam principalmente de adubação que eleve os teores de $\mathrm{Ca}^{2+} \mathrm{e}$ $\mathrm{K}^{+}$, respectivamente.

Os baixos teores de matéria orgânica e muito baixos de fósforo nos solos são os principais limitantes à produção agrícola dos pomares estudados.

A textura dos solos varia de franco-arenosa a argilosa, predominando a textura franco-argilo-arenosa, diferenciando o pomar Jussara com a textura mais arenosa.

\section{REFERÊNCIAS BIBLIOGRÁFICAS}

ALVAREZ V., V. H.; NOVAIS, R. F.; BARROS, N. F.; CANTARUTTI, R. B.; LOPES, A. S. Interpretação dos resultados das análises de solos. In: RIBEIRO, A.C. GUIMARÃES, P. T. G.; ALVAREZ V., V. H. Recomendações para o uso de corretivos e fertilizantes em Minas Gerais - $5^{\text {a }}$ aproximação. Viçosa-MG, 23-32p. 1999.

BRONICK, C. J.; LAL, R. Soil structure and management: a review. Geoderma, v. 124, p. 3-22, 2005.

CANELlAS, L. P.; VELlOSO, A. C. X.; MARCIANO, C. R.; RAMALHO, J. F. G. P.; ROUMJANEK, V. M.; REZENDE, C. E.; SANTOS, G. A. Propriedades químicas de um Cambissolo cultivado com cana-de-açúcar, com preservação de palhiço e adição de vinhaça por longo tempo. Revista Brasileira de Ciência do Solo, v.27, n. 5, p.935-944, 2003.

CPRM - Companhia de Pesquisa de Recursos Minerais. Serviço Geológico do Brasil. Projeto cadastro de fontes de abastecimento por água subterrânea. Diagnóstico do Município de Santana do Mundaú, estado de Alagoas / Organizado [por] Mascarenhas, J. C.; Beltrão, B. A.; Souza Junior, L. C.; Galvão, M. J. T. G.; Pereira, S.N.; Miranda, J.L. F. Recife: CPRM/PRODEEM, 2005, 10p.

Empresa Brasileira de Pesquisa Agropecuária EMBRAPA. Centro Nacional de Pesquisa de Solos. Manual de métodos de análise de solos. $2^{\mathrm{a}}$ ed. Rio de Janeiro: EMBRAPA, 1997. 221 p.

FERREIRA, E. P.; FERREIRA, J. T. P.; PANTALEÃO, F. S.; ALBUQUERQUE, K. N.; FERREIRA, A. C. Citricultura em Santana do Mundaú AL: manejo agrícola da laranja lima Citrus sinensis (L.) Osbeck e os desafios para a sustentabilidade da cultura. Revista Enciclopédia biosfera, v. 8, n. 14, p. 203-219, 2012.

GENDASZEK, A. S.; MAGIRL, C. S.; CZUBA, C. R. Geomorphic response to flow regulation and channel and 
floodplain alteration in the gravel-bedded Cedar River, Washington, USA. Geomorphology, v.179, p. $168-185$, 2012.

HORST, W. J.; WANG, Y.; ETICHA, D. The role of the root apoplast in aluminium-induced inhibition of root elongation and in aluminium resistance of plants: a review. Annals of Botany 106: 185-197, 2010.

IBGE - Estatística da Produção Agrícola 2011. Disponível em:<http://www.ibge.gov.br/home/estatistica/indicadores/ agropecuaria/lspa/estProdAgr_201112.pdf $>$. Acesso em 31 de Mar. de 2012.

JACOMINI, P. K. T.; CAVALCANTI, A. C.; PESSOA, S. C. P.; SILVEIRA, C. O. Levantamento exploratório Reconhecimento de solos do Estado de Alagoas. Recife, Centro de Pesquisas Pedológicas, 1975. 531p. (Boletim Técnico, 35).

MEURER, E. J. Potássio. In: FERNANDES, M. S. Nutrição Mineral de Plantas. Sociedade Brasileira de Ciência do Solo, Viçosa-MG, p. 281-295, 2006.

MORGAN, R. P. C. Soil Erosion and Conservation. 3rd edition. Blackwell Publishing, Oxford, 2005. 304 p.

OLIVEIRA, J. B. Pedologia Aplicada. $3^{\circ}$ ed. Piracicaba: FEALQ, 2008, 587p.

PIRES, F. R.; SOUZA, C. M. Práticas mecânicas de conservação do solo e da água. $2^{\mathrm{a}}$ ed, Viçosa-MG, 2006, $216 \mathrm{p}$.

POLITANO, W.; PISARRA, T. C. T. Avaliação por fotointerpretação das áreas de abrangência dos diferentes estados da erosão acelerada do solo em canaviais e pomares de citros. Engenharia Agrícola, v.25, n. 1, p. $242-$ $252,2005$.
RAMOS, S. J.; ALVES, D. S.; FERNANDES, L. A.; COSTA, C. A. Rendimento de feijão e alterações no $\mathrm{pH}$ e na matéria orgânica do solo em função de doses de composto de resíduo de algodão. Ciência Rural, v. 39, n. 5, p.1572-1576, 2009.

ROCCUZZO, G.; ZANOTELLI, D.; ALLEGRA, M.; GIUFFRIDA, A.; TORRISI, B.F.; LEONARDI, A.; QUINONES, A.; INTRIGLIOLO, F.; TAGLIAVINI, M. Assessing nutrient uptake by field-grown orange trees. European Journal of Agronomy, v. 41, p. 73-80, 2012.

SANTOS FILHO, H. P. S.; MAGALHÃES, A. F. J.; COELHO, Y. S. Citros: O produtor pergunta, a Embrapa responde. Brasília - DF: Embrapa Informações Tecnológicas, 2005. 219p.

SEPLANDE - Secretaria de Estado do Planejamento e do Desenvolvimento Econômico. Disponível em <http://www.seplande.al.gov.br/>. Acesso em 14 de Abr. de 2011.

SAYGINA, S. D.; CORNELISB, W. M.; ERPULA, G.; GABRIELS, D. Comparison of different aggregate stability approaches for loamy sand soils. Applied Soil Ecology, v. 54, p. 1-6, 2012.

SOUZA, L. D.; RIBEIRO, L. S.; SOUZA, L. S.; LEDO, C. A. S. \& CUNHA SOBRINHO, A. P. Distribuição das raízes dos citros em função da profundidade da cova de plantio em Latossolo Amarelo dos Tabuleiros Costeiros. Revista Brasileira de Fruticultura, v. 28, n. 1, p. 87-91, 2006. 